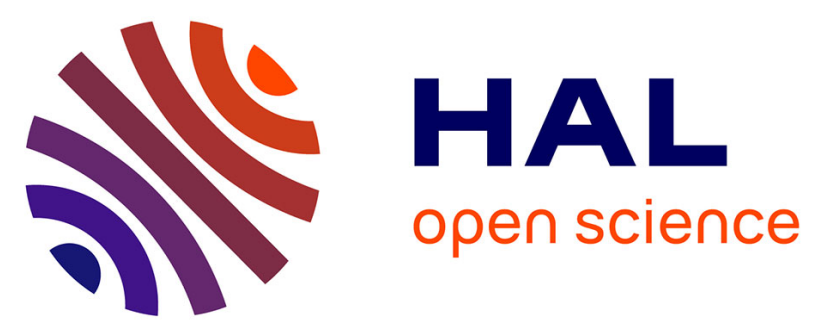

\title{
Potential of a spectroscopic measurement method using Adding-Doubling to retrieve the bulk optical properties of dense microalgal media
}

\author{
S. Bellini, R. Bendoula, E. Latrille, J.M. Roger
}

\section{> To cite this version:}

S. Bellini, R. Bendoula, E. Latrille, J.M. Roger. Potential of a spectroscopic measurement method using Adding-Doubling to retrieve the bulk optical properties of dense microalgal media. Applied Spectroscopy, 2014, 10 (68), pp.1154-1167. hal-01082935

\section{HAL Id: hal-01082935 \\ https://hal.science/hal-01082935}

Submitted on 14 Nov 2014

HAL is a multi-disciplinary open access archive for the deposit and dissemination of scientific research documents, whether they are published or not. The documents may come from teaching and research institutions in France or abroad, or from public or private research centers.
L'archive ouverte pluridisciplinaire HAL, est destinée au dépôt et à la diffusion de documents scientifiques de niveau recherche, publiés ou non, émanant des établissements d'enseignement et de recherche français ou étrangers, des laboratoires publics ou privés. 


\title{
Potential of a spectroscopic measurement method using Adding-Doubling to retrieve the bulk optical properties of dense microalgal media
}

\author{
Sarah Bellini* · Ryad Bendoula · Eric Latrille · Jean-Michel Roger \\ S. Bellini $\cdot$ R. Bendoula $\cdot$ J.M. Roger \\ IRSTEA UMR ITAP \\ 361 rue Jean-François Breton - BP5095 F-34093 Montpellier France Tel.: +334-67-046377 \\ E-mail of the corresponding author: sarah.bellini@irstea.fr \\ E. Latrille \\ INRA, UR50 Laboratoire de Biotechnologie de lâEnvironnement \\ F-11100 Narbonne, France Avenue des Etangs, Narbonne
}

\begin{abstract}
:
In the context of algal mass cultivation, current techniques used for the characterization of algal cells require time-consuming sample preparation and a large amount of costly, standard instrumentation.

As the physical and chemical properties of the algal cells strongly affect their optical properties, the optical characterization is seen as a promising method to provide an early diagnosis in the context of mass cultivation monitoring. This article explores the potential of a spectroscopic measurement method coupled with the inversion of the radiative transfer theory for the retrieval of the bulk optical properties of dense algal samples. Total transmittance and total reflectance measurements were performed over the 380-1020nm range on dense algal samples with a double integrating sphere setup. The bulk absorption and scattering coefficients were thus extracted over the 380-1020nm range by inverting the radiative transfer theory using inverse-adding-doubling computations. The experimental results are presented and discussed: the configuration of the optical setup remains a critical point. The absorption coefficients obtained for the four samples of this study appear not to be more informative about pigment composition than would be classical methods in analytical spectroscopy, however there is a real added value in measuring the reduced scattering coefficient, as it appears to be strongly correlated to the size distribution of the algal cells.
\end{abstract}

\section{Keywords:}

Dense microalgal culture monitoring; multiple light scattering; inverse adding-doubling; bulk optical properties; radiative transfer theory

\section{Introduction}

Autotrophic microalgae are seen as a promising source of biomass for various applications such as high-value chemicals extraction, ${ }^{1}$ animal and human food ${ }^{2}$ and energy production. ${ }^{3}$ Consequently, the global mass production of microalgae has largely increased over the last decade. ${ }^{3}$ However, the current techniques used for the characterization of the algal cells all along the growth process require time-consuming sample preparation, a large amount of costly, standard instrumentation and cannot usually be performed in situ.

New tools are needed to optimize the monitoring of the cultivation process by providing a faster and simpler measurement of the microalgal cells physical and chemical states. For this purpose, utilizing visible (VIS) and near infrared (NIR) spectroscopy ${ }^{4}$ is looked as a promising solution since the measurements can be performed 
with minimum or no sample preparation, with instruments presenting a high signal-to-noise ratio. Moreover, previous studies demonstrated that the absorption and scattering coefficients of microalgal suspensions in the VIS-NIR domain depend heavily on the chemical characteristics ${ }^{5,6}$ (mainly nature and concentration of pigments) and physical characteristics ${ }^{4,-14}$ of the cells (size, density of the cells). Retrieving the bulk optical properties of dense microalgal media has great potential for the advanced diagnosis in micro-algae cultivation processes. ${ }^{6,15,16}$

In a context of an algal cultivation process, cell density is very high $\left(10^{6} \bar{\top} 10^{9} \mathrm{cell} / \mathrm{mL}\right)$ which makes the scattering phenomena signiýcant. Recent studies ${ }^{17}{ }^{18}$ have showed that the data extraction from spectroscopic measurements performed on turbid samples is highly complicated by the influence of the scattering phenomena on the spectra. Yet, several studies ${ }^{19-21}$ demonstrated that the separate consideration of the absorption and scattering coefficients could greatly improve the extent of information extracted from the spectral measurements. In particular, the prospects of a method to retrieve the bulk optical properties from diffuse reflectance and transmittance measurement by inverting the radiative transfer equation have been showed ${ }^{22}$ for the monitoring of bacterial growth.

Several research groups have investigated methods to measure simultaneously the absorption and scattering properties of algal samples. ${ }^{6,23,24}$ However, they generally involve sample preparation such as ýltering ${ }^{25}$ or may have to be combined with additional measurements in order to determine completely both the absorption and scattering signals. ${ }^{26}$ Certain technical difficulties ${ }^{23,27}$ still have to be overcome in the measurement of scattering.

This study is a first approach to investigate the potential of a spectroscopic method coupled with inverse-addingdoubling (IAD) computation ${ }^{28}$ applied to microalgal samples. The method is tested on four dense microalgal samples over the [380-1020nm] range. The soundness of the absorption and reduced scattering coefficient spectra obtained is analyzed. The interest of using these coefficients to characterize the algal samples in addition or in place of classical spectral measurement is also investigated.

This study shows that the method remains hard to apply in practice. The configuration of the optical setup ${ }^{29}$ is a critical point that may be difficult to achieve properly, what can introduce significant light losses in the measurements and errors in the estimation of the absorption and reduced scattering coefficient absolute values ${ }^{30}$. The absorption coefficients obtained for the four samples of this study appear not to be more informative about pigment composition than would be classical methods in analytical spectroscopy, like processing on reflectance and transmittance spectra. However there is probably a real added value in measuring the reduced scattering coefficient, as it appears to be strongly correlated to the size distribution of the algal cells.

\section{Theory}

Microalgal cells can be considered as suspended particles in water that significantly absorb and scatter incident light. In that case, the transport theory ${ }^{31}$ is the rigorous expression of the light radiance variation in space:

$$
\frac{\mathrm{d}(,, \lambda)}{\mathrm{d}}=-\mu \quad \lambda . \quad,, \lambda+\frac{\mu \lambda}{4 \pi} \quad\left(,^{\prime}\right)\left(,^{\prime}, \lambda\right) \mathrm{d} \omega \mathrm{Nij} \varepsilon,, \lambda
$$

Where $I(r, \mathbf{s}, \gamma)$ is the spectral radiance at point $r$ of input radiation propagating along direction $\mathbf{s}, \quad(, \quad)$ is the phase function measuring the angular distribution of scattered light with respect to the input direction, $\mu_{\mathrm{ext}}(\partial)$ $\left[=\mu_{\mathrm{a}}(\partial)+\mu_{\mathrm{s}}(\partial)\right]$ is the bulk extinction coefficient, $\mu_{\mathrm{s}}(\partial)\left(\mathrm{mm}^{-1}\right)$ is the bulk scattering coefficient, $\mu_{\mathrm{a}}(\partial)\left(\mathrm{mm}^{-1}\right)$ is the bulk absorption coefficient and $\varepsilon, \lambda$ is a source term. In this study, the phenomena of fluorescence introduced by the photopigments were considered as negligible, which sets the source term to zero.

For a medium composed of different species, the usual assumption ${ }^{20}$ is to consider that the bulk scattering and absorption coefficients are the sums of the coefficients of each individual species $j$ : 


$$
\begin{aligned}
& \mu \lambda=\mu,(\lambda) \\
& \mu \lambda=\mu,(\lambda)
\end{aligned}
$$

The phase function $\mathrm{p}$ can be approximated by a function of the scattering angle ofand the anisotropy factor $g$ (defined as $=<\cos \theta>$ ). It is usual to choose the empirical Henyey-Greenstein phase function ${ }^{32}$ expressed by:

$$
(\cos \theta)=0.51-(1+\quad-2 \cos \theta)
$$

It is usual to define also the reduced scattering coefficient $\mu_{\text {sô }}$ such that:

$$
\mu=\mu(1-)
$$

Equation (1) thus describes spectral radiance of a beam as it propagates inside a medium as a function of the bulk optical properties, $\mu_{\mathrm{a}}, \mu_{\mathrm{s}}$ and $g$ of that medium. With proper boundary conditions depending on the geometry of the system, it is possible to retrieve the light variations when $\mu_{\mathrm{a}}, \mu_{\mathrm{s}}$ and $g$ of the sample are known. Adding-doubling method was introduced in atmospheric sciences by van de Hulst ${ }^{33}$ to solve the transport equation in slab geometry. A comprehensive software was developed by Prahl ${ }^{34}$ for his own work on light distribution in biological tissues and is available on the website http://omlc.ogi.edu/software/. The method is adapted to solve (1) in any situation with no restriction on the ratio between scattering and absorption, no restriction on the scattering anisotropy and it includes repection at the boundaries of the sample. A reduced set of assumptions $^{35}$ specifies the scope of validity of the method: no time dependence, description of the sample as the union of optically uniform layers of ýnite thickness and inýnite extent along directions parallel to the surface, uniform illumination by collimated or diffuse light.

In adding-doubling theory, the reflection and transmission properties of a slab are described by its reflection and transmission matrices that give the signals reflected and transmitted by the slab at different solid angles in space.

If the transmission and repection matrices of two individual layers are known, one can compute the successive repection and transmission between the two layers and can thus deduce the repection and transmission matrices of their combination. With that principle, the repection and transmission properties of a homogenous slab of sample of thickness z can be computed by starting with an inýnitely thin layer represented by its optical characteristics: the anisotropy factor $g$, the albedo $a$ and the optical thickness Üsuch that:

$$
\begin{gathered}
=\mu+\mu d \\
=\frac{\mu}{\mu+\mu}
\end{gathered}
$$

With $\mathrm{d} z$ the unite thickness of the slab. Equation (1) can be discretised for an infinitely thin layer and solved thanks to the diamond initialization method. ${ }^{36}$ The reflection and transmission matrices of the initialization layer are thus obtained.

Once the repection and transmission of the initialization layer are known, it is possible to calculate the new reflection and transmission matrices of the combination of two initialization layers. By iterating that process one can calculate the reflection and transmission matrices of any slab of thickness $z$. 
The inverse problem is the retrieval of the bulk optical coefficients from measurements describing light variations in space: it can be solved with inverse-adding-doubling. ${ }^{28}$ The radiance throughout the sample can be characterized by measuring total repectance , total transmittance and regular transmittance with a dedicated double integrating sphere setup. In that case the inversion makes it possible to retrieve all three coefficients $\mu_{\mathrm{a}}, \mu_{\mathrm{s}}$ and $g$. The inverse algorithm first calculates with the adding-doubling principle the values of total reflectance and total transmittance from an initial triplet of optical characteristics $(a, \mathrm{U} g)$. The error between the estimated reflectance and transmittance and the measured values is then estimated by the quantity $M$ :

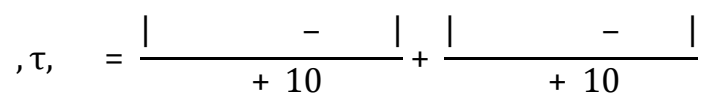

The optimization of the triplet $(a, \mathrm{U} g)$ is obtained by minimizing the error $M$ by means of an $\mathrm{n}$-dimension minimization algorithm. It is thus possible to deduce a triplet of optical characteristics $(a$, Ŭ $g$ ) that matches the one of the measured sample.

Because the measurement of $T_{\text {coll }}$ is generally problematic, ${ }^{20}$ it is also usual to apply inverse adding-doubling with only two measurements ( $\mathrm{of} R_{\mathrm{tot}}$ and $T_{\mathrm{tot}}$ ). In that case, the anisotropy coefficient $g$ is fixed and only the absorption coefficient $\mu_{\mathrm{a}}$ and the reduced scattering coefficient $\mu_{\mathrm{so}}$ are calculated by the inversion process. As illustrated by the study of Dzhongova et al. ${ }^{37}$ and as discussed by Prahl, ${ }^{35}$ using poor collimated transmittance signals with inverse-adding-doubling method generates many errors in the computation of scattering and absorption coefficients. Better results are obtained by only using and and approximating the phase function $p$ with the empirical Henyey-Greenstein phase function. ${ }^{32}$ That is why the latter solution was implemented in the case of this study.

\section{Material and methods}

Experimental design

Four mixed populations of Scenedesmus and Chlorella were grown in four distinct external ponds numbered S1, S2, S3 and S4, at Laboratoire de Biotechnologie de lâEnvironnement (LBE), Narbonne (INRA France). Illumination was provided by the sun and no speciýc temperature regulation was applied. Mixing and bubbling were carried out with a pump system. Nutrients were provided by regular inputs of fertilizer (ANTYS®8, Fertil France). Samples were taken at 3 p.m. from each pond and entirely characterized using standard methods in the shortest time possible in order to minimize the impacts caused by a change in the algal culture environment. In the meantime the spectroscopic measurements of $R_{\mathrm{tot}}$ and $T_{\mathrm{tot}}$ were performed on each sample.

Measurement of total repectance and total transmittance spectra

Optical setup

A detailed description of the optical measurement setup and its principle can be found elsewhere. ${ }^{29,}{ }^{38}$ Figure 1 illustrates the different measurement conýgurations. Total repected signal $I_{\mathrm{R}, \mathrm{tot}}$ was collected in the ýrst integrated sphere (Figure 1 (a)) in contact with the sample side reached by the incident light beam $I_{0}$. The incident light beam was tilted with an angle of of $8^{\circ}$ from the optical axis to ensure that the regular reflected signal (1) was collected inside the reflectance sphere. Total repectance signal $I_{\mathrm{R}, \mathrm{tot}}$ thus measured included both regular (1) and diffuse (2) repected light. Total transmitted signal $I_{\mathrm{T}, \text { tot }}$ was collected with the second integrating sphere (Figure 1 (b)) aligned with the incident beam direction and in contact with the other side of the sample. $I_{\mathrm{T}, \mathrm{tot}}$ included both regular (3) and diffuse (4) transmitted light. Total reflectance $R_{\mathrm{tot}}$ and total transmittance $T_{\text {tot }}$ were calculated such that:

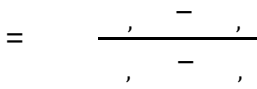




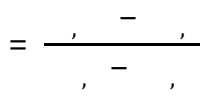

Where $I_{R, \text { std }}$ is the signal measured in the reflectance sphere when the sample is replaced by a standard reflectance. The standard reflectance used in this study was a spectralon (LabSphere) with a spectral reflectivity $r_{\text {std }}$ close to 0.98 on the spectral domain considered. The values of $r_{\text {std }}$ were provided by the manufacturer. $I_{\mathrm{T}, 1}$ is the signal measured in the transmittance sphere when the input beam directly reaches the transmittance sphere (sample removed). $I_{\mathrm{R}, 0}$ and $I_{\mathrm{T}, 0}$ are the signals measured respectively in the reflectance and transmittance spheres when the input light beam $I_{0}$ is stopped.

The double integrating sphere configuration imposed that the sample cell was positioned outside of the spheres: in practice this meant that for one sphere, the actual solid angle where the reflected or transmitted light was collected was smaller than $2^{\prime}$ sr. A significant amount of light ((5) on figure 1) could thus leak in directions that were not detected by the spheres, at the edges of the sample cell and at the sphere ports. In order to limit at best those effects, the sample cell thickness, the sample cell position, the incident light beam size upon the sample and the diameters of the spheres ports were carefully adapted. In the case of this study, the solid angle detected by one sphere could be optimized to reach approximately $1.7^{\prime} \mathrm{sr}$.

Ten measurements of $R_{\mathrm{tot}}$ and $T_{\mathrm{tot}}$ were collected for each sample, what made it possible to limit the effects of the experimental conditions. The measurements were conducted using $30 \mathrm{~mm}$ - diameter repectance and tramsittance spheres (AvaSphereī 30, Avantes) ýbered with 1mm-core low OH optical ýbers (Ocean Optics). Illumination was provided by a tungsten halogen light source (HL ï 2000, Ocean Optics) and the spectral acquisition was carried out using a spectrometer (MMS1, Zeiss). The temperature fluctuations of the light source were limited by turning on the lamp at least one hour before beginning the measurements: this lapse of time was observed to be sufficient for the light source to be as stable as possible. The integration time varied between 4000 and $6500 \mathrm{~ms}$ depending on the signal measured. Liquid samples were put in quartz cells (100ī QS, Hellma) with a 10mmoptical thickness and maintained between the two spheres thanks to a customized cell holder ýtted to the bench dimensions. The measurements were made in the spectral region between 380 and $1020 \mathrm{~nm}$ with $10 \mathrm{~nm}$ resolution intervals and $3 \mathrm{~nm}$ step intervals.

Determination of the errors in the spectroscopic measurement procedure

Ten measurements of $T_{\text {tot }}$ spectra were conducted on the same algal sample and put in a matrix $\mathbf{X}$ with dimension $10 \mathrm{xp}$ where $\mathrm{p}$ is the number of wavelengths:

$\mathbf{X}$ was analyzed by means of a Principal Component Analysis (PCA) ${ }^{39}$ which made it possible to approximate it by the matrix such that:

Where $\mathbf{S}$ and $\mathbf{L}$ are respectively the matrices of the scores and of the loadings, and $\mathrm{k}$ the number of loadings. The loadings obtained were the eigenvectors describing a new linear vector space where $T_{\text {tot }}$ spectra were represented by the values of their scores, which were their coordinates in that space. The advantage of the vector space found with PCA was that it had a smaller dimension than the original space of description of the $T_{\text {tot }}$ spectra and was thus easier to analyze.

A hundred noise spectra were then simulated by randomly choosing the values of the scores, and put in the matrix $\mathbf{N}$ :

$$
\times=0 \times 0,1 \times() \times \times
$$


Where 2 is a normal law centered on zero with standard deviation 1 and the diagonal matrix of the scores satandard deviation values. Those simulated noise spectra were added to an averaged $T_{\text {tot }}$ spectrum in order to simulate a hundred replicates of total transmittance measurements on the same sample.

The spectral standard deviation of the set of $T_{\text {tot }}$ spectra stored in $\mathbf{M}_{\text {Ttot }}$ was then calculated and used to characterize the errors on the measurement procedure of $T_{\text {tot }}$. The same method was applied to estimate the error on the total reflectance measurement, and the matrix $\mathbf{M}_{\text {Rtot }}$ of one hundred simulated $R_{\mathrm{tot}}$ spectra was calculated. This procedure was conducted for the four algal samples: for each sample the $\mathbf{M}_{\text {Ttot }}$ and $\mathbf{M}_{\text {Rtot }}$ matrices were obtained.

Computation of absorption and reduced scattering spectral coefficients

Inverse-adding-doubling computations were performed on the measured spectra of $R_{\mathrm{tot}}$ and $T_{\text {tot }}$ using software developed by Prahl ${ }^{34}$ and run with MatLab (R2012b version). The real part of the refractive index of the cell slab was set as 1.46 according to manufacturer data and considered as constant over the spectral region studied. The real part of the refractive index of the sample solutions was measured at $598 \mathrm{~nm}$ using an Abbe refractometer (NAR-1T, Atago) and assumed to be constant as well over the visible spectral range, and set as $n_{\text {algal sample }}=1.334$. According to the measurements published by Lee et al., ${ }^{15}$ the anisotropy factor $g$ was fixed to 0.98 throughout the $[380-1020 \mathrm{~nm}]$ spectral domain.

Propagation of the measurement procedure errors in the IAD computation

For each sample, the impact of the measurement errors on the IAD results was estimated by calculating the absorption and scattering coefficient spectra of a hundred possible doublets of $R_{\mathrm{tot}}$ and $T_{\mathrm{tot}}$. Those doublets were built by randomly associating a vector of the matrix $\mathbf{M}_{\text {Ttot }}$ to a $R_{\text {tot }}$ coming from $\mathbf{M}_{\text {Rtot }}$.

For each sample, one hundred spectra of possible absorption coefficient and one hundred spectra of possible reduced scattering coefficient were obtained. It was thus possible to estimate the variation of the $\mu_{\mathrm{a}}$ and $\mu_{\mathrm{so}}$ spectra originating from the errors in the measurements. The mean value and the standard deviation of the $\mu_{\mathrm{a}}$ and $\mu_{\text {sô }}$ spectra were calculated.

Measurement of cell number and size

Cell number and size of each sample were determined by mean of a Z2 Coulter Counter (Beckman Coulter): samples were diluted in isotonic solution by a factor of $1 / 200$ and the counting was carried out on a $0.5 \mathrm{~mL}$ volume aliquot. The particle volume was represented in terms of equivalent spherical diameter (ESD), i.e. the diameter of the sphere having the same volume as the particle of interest. By summing the volumes occupied by the cells of increasing size, the total biovolume of the sample was obtained (ýgure 2). The size distribution was calculated by normalizing by the total biovolume (ýgure 3). Microscopic observations and counting were conducted concurrently using a BX40 phase-contrast microscope (BX40, Olympus) and Toma counting cells.

Measurement of Chlorophyll concentrations

Chlorophyll a ( Chl a ) and chlorophyll b ( Chl b) contents of the algal samples were determined through pigment extraction and colorimetric measurements. Solutions containing $2 \times 10^{6}$ cells were obtained after centrifugation $(19000 \times \mathrm{g}, 10 \mathrm{~min}) .1 \mathrm{~mL}$ of acetone was added and mixed by vortexing. The volume solution was completed at $2 \mathrm{~mL}$ with acetone and mixed again. The sample was then put in ultrasound tub for 60min and centrifuged (19000 
$\times \mathrm{g}, 8 \mathrm{~min}$ ). Absorption coefficient of the obtained supernatant at $664 \mathrm{~nm}$ and $647 \mathrm{~nm}$ was then measured using a Shimadzu spectrophotometer, and correction was applied by subtracting acetone absorption. The pigment concentrations $[C h l a]$ and $[C h l b]$ were calculated using the spectrophotometric equations of Porra et al. ${ }^{40}$

The intracellular pigment concentration was computed according to Bricaud et al. deýnition ${ }^{6}$ :

$$
0=0 \frac{. \pi}{6}
$$

Where $N / V$ is the cell number density in the medium, $d$ the mean cell diameter (m) and [Chl] the concentration of chlorophyll in the extraction $\left(\mathrm{g} \cdot \mathrm{m}^{i 3}\right)$.

\section{Results and discussion}

Sample characteristics

Sample composition

Microscopic observations revealed that the main mesoscopic constituents of the samples were microalgal cells: no signiýcant amount of detrial particles was observed, and no particular bacterial population was detected, which was conýrmed by the granulometric results indicating no signiýcant amount of small particles $(<3 \mu \mathrm{m})$. In a ýrst approach, the samples were thus considered to be exclusively composed of algal cells and water. The impact of dissolved nutrients was also judged negligible in the framework of this study.

\section{Cell size distribution}

On the ordinate axis, ýgure 2 shows the total biovolume in $\mathrm{mm}^{3}$ taken up by algal cells whose diameters are inferior to the value given on the abscissa axis. Cell diameters are distributed over a range from $3 \mu \mathrm{m}$ to $10 \mu \mathrm{m}$. Total biovolume is read for $\mathrm{x}=10 \mu \mathrm{m}$. Sample S4 biovolume is the smallest. S2 and S3 present the same total biovolume. Figure 3 shows the same results but this time the biovolume is normalized by the total biovolume: this makes it possible to directly compare the size distribution proýles of the cells in the different sample algal suspensions. Consequently we observe that $\mathrm{S} 3$ biovolume is mainly made up of big cells, whereas $\mathrm{S} 2$ biovolume principaly consists of small cells. This indicates that two pairs of samples can be clearly differentiated: the pair 1ī 4 with samples having similar size distribution proýles but signiýcantly different total biovolumes, and the pair 2 i 3 with samples presenting considerably distinct size distribution proýles but similar total biovolumes.

\section{Chlorophyll concentrations}

Table I shows the intracellular pigment concentrations measured for $C h l a$, Chl $b$ and the total pigment concentration, approximated as the sum of the two chlorophylls.

The four sample algal populations are distinctly pigmented: the intracellular total chlorophyll concentration for $\mathrm{S} 4$ is 6 times that of S1 and S3 and reaches the value of $12.2 \pm 0.6 \times 10^{3} \mathrm{~g} . \mathrm{Chl} . \mathrm{m}^{i}$. S1 and S3 present intracellular total pigment rates that are comparable. However $\mathrm{Chl}$ a proportion is much higher in $\mathrm{S} 1$ (74\% of total pigment) than in S3 (64\% of total pigment). S2 has the lowest concentration in chlorophyll with an intracellular total pigment concentration that is half those of $\mathrm{S} 1$ and $\mathrm{S} 3$, for a value of $1.03 \pm 0.05 \times 10^{3} \mathrm{~g} . \mathrm{Chl} . \mathrm{m}^{i 3}$.

Raw reflectance and transmittance spectra

Total transmittance and total reflectance

Total transmittance and total repectance spectra were measured using the double-integrating sphere setup. Figure 4 (a) shows the raw total reflectance spectra measured for the four samples. The error bars are set to plus or minus twice the standard deviation. 
For the four samples, the measurements were made with a relative error that does not exceed $6 \%$ of the value on the [400-950nm] spectral range. As expected, the uncertainty grows dramatically at the upper and lower limits of the detection range of the spectrometer, reaching up to $20 \%$ at $1020 \mathrm{~nm}$ and $10 \%$ at $380 \mathrm{~nm}$. The position of the sample cell, the fluctuations in time of the light source and the noise of the spectrometer at the limits of its detection bands were identified as the major experimental factors introducing variation in the measurements. It had been observed that the angular position of the sample significantly influenced the signals measured, and particularly the regular reflected signal. This explained why a small angular deviation of the cell would dramatically change the amount of total reflected light collected in the sphere. Therefore, special care was taken in positioning the sample cell at each replicate to limit the impact of the cell position.

$R_{\text {tot }}$ spectra consistently illustrate the chemical composition of the samples: they show three major spectral regions where the reflected signal is lower: the $[400-550 \mathrm{~nm}],[650-700 \mathrm{~nm}]$ and $[900-1020 \mathrm{~nm}]$ bands. This originates from the significant absorption phenomena occurring at these wavelengths, due to the presence of pigments ([400-550nm] and [650-700nm] bands) and water ([900-1020nm] band) in the samples.

Figure 4 (b) shows the raw total transmittance spectra. As previously the error bars show plus or minus twice the standard deviation.

The measurements of $T_{\text {tot }}$ were conducted with a relative error lower than $4 \%$ throughout the [400-1000nm] spectral domain. As for $R_{\mathrm{tot}}$, the limitation of the spectrometer introduces higher uncertainty for the lower wavelengths. $T_{\text {tot }}$ measurements appear to be less sensitive to the experimental conditions than $R_{\text {tot }}$ measurements. This is explained by the fact that the Signal To Noise (SNR) ratio is higher for the $T_{\text {tot }}$ than for $R_{\text {tot }}$ due to higher levels. Moreover, the transmitted signal collected is less dependent on the angular cell position than $R_{\text {tot. }}$

$T_{\text {tot }}$ spectra show the same absorption bands as observed for $R_{\text {tot }}$.

Figure 5 (a) shows the fraction of incident light that has not been collected in the double-sphere setup: it is expressed as $1-\left(R_{\mathrm{tot}}+T_{\mathrm{tot}}\right)$. It can be seen that less than $100 \%$ of the incident light is actually detected by the measurement system, which originates from expected absorption phenomena inside the sample as well as supplementary, unwanted light losses depending of the configuration of the optical setup.

A qualitative analysis of the shape of the spectra makes it possible to identify three major effects, as shown by figure 5 (b): a baseline, a decreasing trend with increasing wavelength and absorption peaks.

The baseline indicates that a portion of incident light has been lost in a way that does not depend on the wavelength. Those losses may originate from the geometrical configuration of the measurement setup and the thickness of the sample as explained previously.

The linear decreasing trend with increasing wavelength may represent light losses due to scattering phenomena, that are expected to be wavelength dependant and higher in the lower wavelengths. A linear approximation of the four different spectra shows that the slope is the highest for sample S4. In decreasing order come S3, S1 and S2.

Finally, a significant amount of light is absorbed within the sample with a particular spectral pattern depending on the chemical absorbers. The three majors absorption bands previously identified are also clearly visible on the spectra.

The first and second derivatives are usual preprocessing methods in analytical spectroscopy to remove additive effects on the spectra ${ }^{41}$. The first derivative removes only the baseline and the second derivative removes both baseline and linear trend. It can be achieved by the Savitzky-Golay derivation method. ${ }^{42}$ Figure 5 (c) shows the spectra obtained by calculating the second derivative of the quantity $1-R_{\mathrm{tot}}-T_{\text {tot. }}$ Eight main absorption peaks can thus be identified, and are presented in table II. They are consistent with many studies on microalgal pigments reported in Aguirre-Gomez et al. ${ }^{43}$ Peaks 1, 4,5 and 6 (Table II) correspond to in vivo absorption by Chl $a$. Peak 2 is clearly attributable to $C h l b$. The $590 \mathrm{~nm}$ peak could be attributed to $\mathrm{Chl} a-\mathrm{Chl} c$ or to carotenoid-like pigments. Peak 8 corresponds to absorption by water. 
The values of the peaks may be linked to the quantity of absorbers inside the samples. If we compare the values of the spectra of the different samples at Chla main absorption peaks (1 and 6), it seems that sample S4 is the most concentrated in Chla and sample S2 is the least pigmented. It is difficult to conclude something about S3 and $\mathrm{S} 1$ as their relative position does not remain the same at peak 1 and 6. At 492nm the values of the peaks may indicate the Chlb level of the samples: here again, S4 is clearly more pigmented than S2, S1 and S3, while S2 is the least pigmented. S1 and S3 seem to have quite similar Chlb levels. Those results are consistent with the pigment concentrations measured and shown in table I.

Absorption and reduced scattering coefficient spectra

Convergence of the IAD algorithm

Figure 6 shows the absorption (a) and reduced scattering (b) coefficient spectra obtained after IAD computations. The mean absorption and reduced scattering spectra were computed for the samples throughout the spectral range [380-1020nm]. The error bars represent plus or minus twice the standard deviation obtained by repeating one hundred times the IAD computations as explained previously.

It has to be noted that convergence of the inverse-adding-doubling program appears to be erroneous for sample S2 beyond $x=700 \mathrm{~nm}$ since the reduced scattering coefficient obtained is null. This indicates that the results computed with the IAD in the case of this study must be handled critically. In particular, the effect of the unwanted light losses in the measurement setup described previously (figure 1, (5)) has to be taken into consideration. The study of de Vries et al. ${ }^{30}$ showed that in the case of samples with low absorption and high scattering coefficients, those unwanted light losses may be interpreted by the IAD algorithm as absorption phenomena inside the sample rather than losses in the outside world, which would lead to an overestimation of the absorption coefficient. The quantitative values of the $\mu_{\mathrm{a}}$ and $\mu_{\mathrm{so}}$ computed with IAD may then be dependent on the optical setup with which the measurements were conducted. It can also be conjectured that the results obtained with a given optical setup for two objects with different ranges of optical characteristics (distinct order of magnitude for the optical thickness and albedo) could not be compared. This is why the absorption and reduced scattering coefficients computed in the framework of this study should only be treated qualitatively.

\section{Absorption}

From figure 6 (a) it can be seen that the relative estimation error on the $\mu_{\mathrm{a}}$ values computed largely depend on the wavelength. It is quite high throughout the spectrum (more than $6 \%$ and up to $17 \%$ at $750 \mathrm{~nm}$ ) except on the main absorption bands (the [400-550nm], [650-700nm] and [900-1000nm] bands) where it is as low as 4\%. This is probably explained by the fact that the absorption coefficient is much higher on those spectral domains, what significantly reduces the relative error.

As what was observed on $R_{\text {tot }}$ and $T_{\text {tot }}$ spectra (figure 4), absorption spectra are mainly shaped by the absorption of the photosynthetic pigments. $\mu_{\mathrm{a}}$ spectra show the same absorption peaks as those previously identified with the second derivative on the raw measurement spectra (table II).

For two samples, the overlap of the error bars indicate that their $\mu_{\mathrm{a}}$ values at that wavelength cannot be considered as different. From this it appears that the $\mu_{\mathrm{a}}$ spectra of the four samples are quite similar throughout the considered spectral domain, except on the [380-550nm] and [650-710nm] bands where they can be distinct. It can be observed in particular that the four $\mu_{\mathrm{a}}$ spectra are completely overlapping on the [900-1000nm] band corresponding to the absorption of water. This is not surprising, as the water volume was significantly higher than the algal volume in the four samples.

The comparison of $\mu_{\mathrm{a}}$ values at peaks 1 and 6 can be done. $\mu_{\mathrm{a}}(\mathrm{S} 1)$ and $\mu_{\mathrm{a}}(\mathrm{S} 2)$ are distinct at peaks 1 and 6 with the following order: $\mu_{\mathrm{a}}(\mathrm{S} 1)>\mu_{\mathrm{a}}(\mathrm{S} 2)$. $\mu \mathrm{a}(\mathrm{S} 1)$ and $\mu_{\mathrm{a}}(\mathrm{S} 3)$ are overlapping at peak 1 and are different at peak 6 where $\mu_{\mathrm{a}}(\mathrm{S} 1)>\mu_{\mathrm{a}}(\mathrm{S} 3)$. It is the same thing for $\mathrm{S} 1$ and $\mathrm{S} 4$, overlapping at peak 1 but distinct at peak 6 with $\mu_{\mathrm{a}}$ $(\mathrm{S} 4)>\mu_{\mathrm{a}}(\mathrm{S} 1) . \mu_{\mathrm{a}}(\mathrm{S} 2)$ and $\mu_{\mathrm{a}}(\mathrm{S} 3)$ are very similar and cannot be distinguished. Again these observations are 
consistent with the pigments measurements given in table I. The information of relative Chla quantity in the samples appears to be more represented by peak 6 .

For Chlb at peak 2 we can only conclude that $\mu_{\mathrm{a}}(\mathrm{S} 1)>\mu_{\mathrm{a}}(\mathrm{S} 2)$ and that $\mu_{\mathrm{a}}(\mathrm{S} 4)>\mu_{\mathrm{a}}(\mathrm{S} 2) ; \mu_{\mathrm{a}}(\mathrm{S} 4)>\mu_{\mathrm{a}}(\mathrm{S} 3)$. S1 and $\mathrm{S} 4$, $\mathrm{S} 1$ and $\mathrm{S} 3$ and $\mathrm{S} 2$ and $\mathrm{S} 3$ are not distinct at $492 \mathrm{~nm}$. This gives a first idea of the results found by the pigment measurement (table I).

As for what was found with the second derivative on $\left(1-R_{\mathrm{tot}}-T_{\mathrm{tot}}\right)$ spectra, the information on relative pigment quantity in the sample given by the analysis of $\mu_{\mathrm{a}}$ spectra is only qualitative. Indeed, $\mu_{\mathrm{a}}$ values are not proportional to the pigment concentrations at absorption peaks: the ratio - at $680 \mathrm{~nm}$ is only 1.42 while the ratio $\frac{(\quad)}{(~) ~ i s ~ 9.4 . ~ T h e ~ a b s o r p t i o n ~ c o e f f i c i e n t ~ s p e c t r a ~ a r e ~ o ̀ p a t t e n e d o ̀ ~ c o m p a r e d ~ t o ~ t h e ~ e x p e c t e d ~ v a l u e s . ~ T h i s ~ i s ~}$ surely explained by an erroneous estimation of the absolute value of $\mu_{\mathrm{a}}$ coefficients by the IAD due to the effect of unwanted light losses in the optical setup.

While remaining critical concerning the $\mu_{\mathrm{a}}$ absolute values computed for the four algal samples in this study, it can be reported still that they seem to be consistent with the results that can be found in literature. This may indicate that the errors of estimation of the $\mu_{\mathrm{a}}$ introduced by the IAD process remain reasonable relatively to the actual value of the absorption coefficient.

In order to take into account the dependency of absorption on the physical structure of the algal population, the dimensionless efficiency factors , and are usually considered. ${ }^{6}$ They are the ratio between the energies that are respectively absorbed, scattered and attenuated within the medium and the input energy. For a suspension of microalgal cells, a simple relation exists between $\mu$ and :

$$
=\underline{\mu,}
$$

Where $\Omega$ is the geometrical cross section of one cell, $N$ the number of cells of uniform size in a volume $V$, and $\mathrm{i}=\mathrm{a}, \mathrm{s}$ or ext. Here $\mu_{\mathrm{i}, \text { eell }}$ is the bulk optical coefficient of one cell. If the algal cells are approximated as spheres the value for $\Omega$ can be easily deduced from the cell diameter $d: \Omega=\pi^{2} / 4$. As the efficiency factors take into account the inpuence of cell size and density in the medium, it is more relevant to use them instead of bulk absorption coefficient $\mu$ in order to compare distinct measurements of the absorption properties of various algal polydispersions. Table III, adapted from the article of Sathyendranath et al. ${ }^{44}$ compares the efficiency factors for absorption obtained in this study with those obtained by other previous studies.

Table III shows that the efficiency factors computed from the measurements on the four samples of this study are consistent with the literature ${ }^{6,42}$ regarding their order of magnitude and their dependency upon the characteristics of the algal population. Fluctuations of the values observed can be both intra and inter species and originate from difference in the relative amount of pigments in the algal cells as well as from variation in the cell density and size between two samples.

\section{Reduced scattering coefficients}

The mean reduced scattering coefficient spectra have been obtained for the four samples and are shown in ýgure 6 (B).

The relative error is higher throughout the spectral domain than it was for $\mu_{\mathrm{a}}$ spectra. It increases with increasing wavelengths, and varies from $5 \%$ at $380 \mathrm{~nm}$ to $17 \%$ at $920 \mathrm{~nm}$ for S4. This trend is explained because the $\mu_{\mathrm{so}}$ values decrease with increasing wavelengths. The relative error for $\mathrm{S} 2$ grows dramatically beyond $700 \mathrm{~nm}$ and exceeds 50\%. This is surely due to convergence failure of the iad computation for sample S2 at higher wavelengths, meaning this part of the spectrum should not be taken into account for S2. 
The four reduced scattering coefficient spectra are more dissimilar the one from the other than what was observed for $\mu_{\mathrm{a}}$ spectra: there is less overlap of the spectra throughout the spectral domain considered. Although S2 and S3 show very similar $\mu_{\mathrm{a}}$ spectra, their $\mu_{\text {sô }}$ spectra seem more distinct the one from the other. On the contrary, S1 and S4 spectra are very similar. However they are distinct from S2 and S3 spectra.

This seems to be explained by the granulometric properties of the samples, and more particularly by the size distribution of the algal cells. Unlike what could have been expected, the total quantity of biomass inside the sample does not appear to be influential on the reduced scattering coefficient in the case of this study: indeed figure 2 shows that $\mathrm{S} 1$ and $\mathrm{S} 4$ have different total biovolumes but their $\mu_{\text {sô }}$ spectra are similar. However, the size distribution of the algal cells is the same for those two samples, as shown in figure 3. On the contrary, S2 and S3 biovolumes are the same but the size distributions of the cells are dissimilar: in that case it is observed that the $\mu_{\text {sô }}$ spectra of S2 and S3 are quite distinct. From this analysis it seems that the size distribution of the algal cells inside the sample is very influential on the values of $\mu_{\text {sô }}$ spectra.

From figure 6 (b) the general shape of $\mu_{\text {sô }}$ spectra can be described: firstly, they are a decreasing function of wavelength and secondly, they show pronounced enhancements in the vicinity of the absorption bands. Unlike what is usually thought in analytical spectroscopy, those peaks in the reduced scattering spectra appear not to be erroneous: they are actually expected, and consistent with the Lorentz-Mie ${ }^{45}$ theory and Ketteler-Helmholtzôs theory of anomalous dispersion. ${ }^{46}$

If the algal cells are considered as homogeneous spheres whose refractive index is close to that of the surrounding medium (here water), their efficiency factors throughout the visible spectrum depend upon the optical size parameter $f$, defined as ${ }^{6,46}$ :

$$
\rho=\frac{2 \cdot \pi \cdot}{\lambda} \cdot(-1)
$$

Where $d$ is the cell diameter, $n$ the real part of the cell complex refractive index relative to water deýned as $=+\quad$ and 2 the wavelength in the surrounding medium. For absorbing particles, the efficiency factors are given $^{46}$ by:

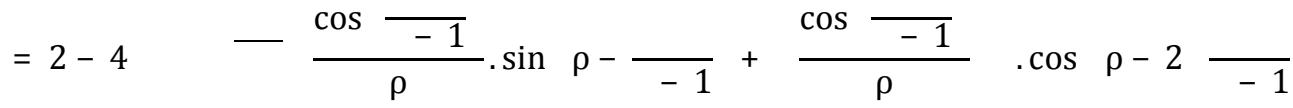

$$
\begin{aligned}
& +4 \frac{\cos \frac{-1}{\rho}}{\rho} \cdot \cos 2 \frac{}{-1} \\
& =1+\frac{-2 \rho \tan \frac{-1}{-1-1}}{2 \rho \tan \frac{-1}{-1}}
\end{aligned}
$$

If the particles are polydisperse with respect to size according to a law $P(\mathrm{f})$, the efficiency factors must be averaged:

$$
-\bar{\rho}=\frac{\rho(\rho) \rho \rho}{(\rho) \rho \rho}
$$


With $\mathrm{i}=\mathrm{a}, \mathrm{s}$ or ext.

Bricaud et al. ${ }^{6}$ computed the variations of the efficiency factors for simulated algal suspensions. They observed different patterns depending on the value of $f$ with respect to the values $\rho$ corresponding to the ýrst maximum in $(\rho)$ :

- If $f$ is lower than $\rho$ throughout the spectrum increases with $f$ i.e. with decreasing $\partial$

- If the range of variation of $f$ includes $\rho$, has a maximum inside the spectrum

- If $f$ remains close to but higher than $\rho$, decreases with increasing $f$, i.e. with decreasing $\ngtr$

- For high values of $f, \quad$ is almost constant throughout the spectrum.

variations (and consequently those of $\mu$ ) follow the same patterns, given by the relationship between and as shown by eq (8). Bricaud et al. ${ }^{6}$ computed that $\rho$ ranges between 2 and 4 and depends on the size distribution law in the case of algal suspensions. , and variations with respect to $f$ were computed in the case of our samples using eq (12), (13) and (14). The example of sample S1 at $\gamma=440 \mathrm{~nm}$ is presented on ýgure 7. It was computed that in the case of our samples, the value of $\rho$ varies slightly around 4 . The computation of $f$ for the four samples presented on ýgure 7 shows that throughout the spectral range of interest, the values of $f$ remain lower than $\rho$, which is consistent with the shape of measured $\mu$ spectra. Over the [380-1100nm] spectral domain it was computed that $f$ ranged between extreme values of 0.5 and 1.8 with slight differences between the samples. This shows the observed decrease of $\mu$ as a function of increasing ris consistent with the predictions given by the Lorentz-Mie theory. ${ }^{45,46}$

The inpuence of an absorption band upon scattering properties has been well described by the same authors. ${ }^{5} \mathrm{By}$ simulating the variations of in the vicinity of an absorption line (occurring at $\gamma=675 \mathrm{~nm}$ ) for various values of $f$ they showed different phenomena may occur depending on the value of $f$ :

- For $f<2$ or 3 the scattering coefficient is enhanced inside and slightly beyond the absorption band, resulting in peaks that may shift slightly towards upper wavelengths compared to the absorption bands.

- $\quad$ For $f>3$ the scattering coefficient is reduced inside the absorption line, which leads to variations of opposite to those of .

In the case of this study, $f$ remains below to two on the considered spectrum, which explains the peaks observed on the reduced scattering spectra measured (ýgure 6) in the vicinity of the absorption bands identiýed in table II.

\section{Conclusion}

This study reports the results obtained while testing the adding-doubling method on the [380-1020nm] spectral range for four non-diluted algal samples extracted from real cultivation ponds. The spectra of absorption and reduced scattering coefficients were computed with inverse-adding-doubling algorithm from total reflectance and total transmittance measurements conducted with a double integrating sphere setup. Several critical points have been encountered, first to optimize the configuration of the optical setup, and second in the convergence of the IAD algorithm from experimental, imperfect measurements of $R_{\mathrm{tot}}$ and $T_{\mathrm{tot}}$.

Because the sample cell is positioned outside of the spheres in the double integrating sphere setup, it is impossible in practice to avoid light losses at the sphere ports and at the edges of the sample cell. These effects are all the more important than the sample is highly scattering. Those losses can be limited at best by adapting carefully the optical setup dimensions. In the case of this study however the light losses remained significant. Light losses within the setup introduce errors in the IAD algorithm convergence and the estimation of the absorption and reduced scattering coefficient absolute values may be erroneous and dependent on the setup with which the optical measurements were conducted..$^{30}$ In the case of this study, the absorption and reduced coefficient spectra obtained could only be qualitatively analyzed.

The absorption coefficient spectra computed represent qualitatively the difference in pigmentation between the four algal samples. However the same results could be obtained with a classical processing on total reflectance 
and total transmittance measurements. Nevertheless it appears that the reduced scattering coefficient may be of interest to extract information on the size distribution of the algal cells. It seems to vary significantly with the granulometric properties of the microalgal samples, thus providing information that could not be extracted from classical measurements. This conclusion is consistent with other works. ${ }^{9,47}$ This could be a promising track to follow up for future application to growth monitoring, and may justify that beyond the complexity in implementing a sound optical setup, adding-doubling could be seen as a potential operational method.

\section{Reference list:}

1. L. Dufossé, P. Galaup, A. Yaron, S. Malis Arad, P. Blanc, K.N. Chidambara Murthy, and G.A. Ravishankar. ñMicroorganisms and microalgae as sources of pigments for food use: a scientific oddity or an industrial reality?ò. Trends Food Sci. Technol. 2005. 16(9):389-406.

2. E.W. Becker. ñMicro-algae as a source of proteinò. Biotechnol. Adv. 2007. 25(2):207-210.

3. J.-P. Cadoret, O. Bernard. ñLa production de biocarburant lipidique avec des microalgues : promesses et défis ». J. Soc. Biol. 2008. 202(3):201-211.

4. P. Williams, K. Norris. In: K. Norris. Near-Infrared Technology in the Agricultural and Food Industries. Amer Assn of Cereal Chemists, St. Paul, Minnesota, 2001.

5. A. Morel, A. Bricaud. ñTheoretical results concerning the optics of phytoplankton, with special reference to remote sensing applicationsò. In: Gower J F R (ed). Oceanography from space. New York : Plenum press, 1981. pp 313-327

6. A. Bricaud, A. Morel, L. Prieur. ñOptical efficiency factors of some phytoplanktersò. Limnol Oceanogr. 1983. 28(5): 816-832.

7. J.R.V. Zaneveld , J.C. Kitchen ñThe variation in the inherent optical properties of phytoplankton near an absorption peak as determined by various models of cell structureò. J Geophys Res. 1995. 100(C7):13309-13320

8. E. Aas. ñnnpuence of shape and structure on light scattering by marine particlesò. Inst. Rep. Ser. 1984., University of Oslo. 53: 112pp

9. A.M. Ciotti, M.R. Lewis, J.J. Cullen. ñAssessment of the relationships between dominant cell size in natural phytoplankton communities and the spectral shape of the absorption coefficientò. Limnol Oceanogr. 2002. 47(2) : 404ї 417.

10. A. Morel, A. Bricaud.ñTheoretical results concerning light absorption in a discrete medium, and application to speciýc absorption of phytoplanktonò. Deep-Sea Res Pt I. 1981. 28(11): 1375-1393.

11. A. Quirantes, S. Bernard. ñLight scattering by marine algae: two-layer spherical and non-spherical modelsò. J Quant Spectrosc Radiat Transfer. 2004. 89(1-4): 311-321.

12. J.T.O. Kirk. ñA theoretical analysis of the contribution of algal cells to the attenuation of light within natural waters. I. General treatment of suspensions of pigmented cellsò. 1975. New Phytol 75(1):11-20.

13. J.T.O. Kirk. ñA theoretical analysis of the contribution of algal cells to the attenuation of light within natural waters. II. Spherical cellsò. New Phytol. 1975. 75(1): 21-36.

14. J.T.O. Kirk.ñA theoretical analysis of the contribution of algal cells to the attenuation of light within natural waters. III. Cylindrical and spheroidal cellsò. New Phytol. 1976. 77(2): 341-358.

15. E . Lee, R.L. Heng, L. Pilon.ñSpectral optical properties of selected photosynthetic microalgae producing biofuelsò. J Quant Spectrosc Radiat Transfer. 2013. 114: 122-135.

16. J-F. Cornet, J. Albiol. ñModeling photoheterotrophic growth kinetics of Rhodospirillum rubrum in rectangular photobioreactorsò. Biotechnol Prog. 2000. 16(2) : 199-207. DOI: 10.1021/bp990148q.

17. M.M. Reis, P.H.H. Araújo, C. Sayer, R. Giudici. ñSpectroscopic on-line monitoring of reactions in dispersed medium: Chemometric challengesò. Anal. Chim. Acta. 2007. 595(1-2): 257-265.

18. B. Lu, S.P. Morgan, J.A. Crowe, I.M. Stockford. ñComparison of Methods for Reducing the Effects of Scattering in Spectrophotometryò. Appl. Spectrosc. 2006. 60(10): 1157-1166.

19. T. Burger, J. Kuhn, R. Caps, J. Fricke. ñQuantitative Determination of the Scattering and Absorption Coefficients from Diffuse Reflectance and Transmittance Measurements: Application to Pharmaceutical Powdersò. Appl. Spectrosc. 1997. 51(3): 309-317. 
Author-produced version of the article published in Applied Spectroscopy, 2014, No 10 (68), p. 1154-1167. The original publication is available at http://www.ingentaconnect.com http://dx.doi.org/10.1366/13-07308

20. R. Steponavicius, S.N. Thennadil. ñExtraction of chemical information of suspensions using radiative transfer theory to remove multiple scattering effects: application to a model two-component systemò. Anal Chem . 2009. 81(18): 7713-7723. DOI: 10.1021/ac9011667.

21. R. Steponavicius, S.N. Thennadil. ñExtraction of chemical information of suspensions using radiative transfer theory to remove multiple scattering effects: application to a model multicomponent systemò. Anal Chem . 2011. 83(6): 1931ї 1937. DOI: 10.1021/ac1024073.

22. E. Dzhongova, C.R. Harwood, S.N. Thennadil. "Changes in the Absorption and Scattering Properties in the Near-Infrared Region During the Growth of Bacillus subtilis in Liquid Culture". Appl. Spectrosc. 2009. 63(1): 25-32.

23. H. Berberoglu, L. Pilon. ñExperimental measurements of the radiation characteristics of Anabaena variabilis ATCC 29413-U and Rhodobacter sphaeroides ATCC 49419ò. Int J Hydrogen Energ. 2007. 32(18): 4772-4785.

24. K.J. Daniel, F.P. Incropera. ñOptical properties measurements in suspensions of unicellular algaeò Tech. Rep., ME-HTL, Purdue University. 1977. 77, 107pp.

25. E. Le Flocôh, G. Malara, A. Sciandra. ñAn automatic device for in vivo absorption spectra acquisition and chlorophyll estimation in phytoplankton culturesò. J Appl Phycol. 2002. 14(6): 435-444. DOI: 10.1023/A:1022338930747.

26. R.J. Davies-Colley. ñOptical properties and reflectance spectra of 3 shallow lakes obtained from a spectrophotometric studyò. New Zeal J Mar Fresh. 1983. 17(4): 445-459.

27. R.J. Davies-Colley, R.D. Pridmore, J.E. Hewitt. ñOptical properties of some freshwater phytoplanktonic algaeò. Hydrobiologia. 1986. 133(2): 165-178. DOI: 10.1007/BF00031865.

28. S.A. Prahl, M.J.C. van Gemert, A.J. Welch. ñDetermining the optical properties of turbid media using adding doubling methodò. App Opt. 1993. 32(4): 559-568. DOI: 10.1364/JOSAA.9.000621.

29. J.W. Pickering, C.J.M. Moes, H.J.C.M. Sterenborg, S.A. Prahl, M.J.C. van Gemert.ñTwo integrating spheres with an intervening scattering sampleò. JOSA A. 1992. 9(4): 621-631. DOI: 10.1364/JOSAA.9.000621.

30. G. de Vries, J.F. Beek, G.W. Lucassen, M.J.C. van Gemert. ñThe effect of light losses in double integrating spheres on optical properties estimationò. IEEE J. Quantum Electron., 5(4),1999.

31. C.F. Bohren, D.R. Huffman. Absorption and scattering of light by small particules. Wiley-VCH. 2008

32. S.T. Flock, B.C. Wilson, M.S. Patterson. ñTotal attenuation coeffcients and scattering phase functions of tissues and phantom materials at 633nmò. Med Phys. 1987. 14(5): 835-841. DOI : 10.1118/1.596010.

33. van de Hulst (1963)

34. S.A. Prahl.ñThe Adding-Doubling Methodò. In: A.J. Welch and M.J.C. van Gemert. Optical-Thermal Response of Laser Irradiated Tissue. Plenum Press, 1995. pp 101-129.

35. S.A. Prahl. ñEverything I think you should know about Inverse Adding-Doublingò. 2011. http://omlc.ogi.edu/software/iad/. Oregon Medical Laser Center. [Accessed 30 Nov 2011]

36. W.J. Wiscombe. ñOn initialization, error and pux conservation in the doubling methodò. J Quant Spectrosc Radiat Transfer. 1976. 16:637-658

37. E . Dzhongova, C.R. Harwood, S.N. Thennadil.ñEffects of sample thickness on the extracted nearinfrared bulk optical properties of bacillus subtilis in liquid cultureò. Appl Spectrosc. 2011. 65(11): 1314-1320.

38. J.W. Pickering, S.A. Prahl, N. van Wieringen, J.F. Beek, H.J.C.M. Sterenborg, M.J.C. van Gemert. ñDouble integrating-sphere system for measuring the optical properties of tissueò. App Opt. 1993. 32(4): 399-410. DOI : 10.1364/AO.32.000399.

39. H. Martens, T. Naes. Multivariate Calibration. Wiley. 1989.

40. R.J. Porra, W.A. Thompson, P.E. Kriedemann. ñDetermination of accurate extinction coefficients and simultaneous equations for assaying chlorophylls a and $b$ extracted with four different solvents: veriýcation of the concentration of chlorophyll standards by atomic absorption spectroscopyò. Biochim Biophys Acta. 1989. 975(3): 384-394.

41. A. Rinnan, F. van den Berg, S. Balling Engelsen. ñReview of the most common pre-processing techniques for near-infrared spectraò. Trends Anal. Chem., 28(10), 2009. 
Author-produced version of the article published in Applied Spectroscopy, 2014, N¹0 (68), p. 1154-1167.

The original publication is available at http://www.ingentaconnect.com

http://dx.doi.org/10.1366/13-07308

42. A. Savitzky, M.J.E. Golay, ñSoothing and differentiation of data by simplified least squares proceduresò. Anal. Chem. 36, 1964.

43. R. Aguirre-Gomez, S.R. Boxall, A.R. Weeks. ñIdentiýcation of algal pigments using high order derivativesò. Paper presented at : the Geoscience and Remote Sensing Symposium, Firenze, 10 ï 14 July 1995.

44. S. Sathyendranath, L. Lazzara, L. Prieur. ñVariations in the spectral values of speciýc absorption of phytoplanktonò. Limnol Oceanogr. 1987. 32(2):403-415.

45. G. Mie. ñBeitrage zur optik trüber medien, speziell kolloidaler metallösungenò. Ann. Phys., 25(3), 1908.

46. H.C. van de Hulst. Light scattering by small particles. New York: Wiley, 1957.

47. C. Frankovitch, O. Reich, H.G. Löhmansroben. ñnvestigation of microalgae with photon density wavesò. Optics for Natural Resources, Agriculture, and Foods II. 2007. 10.1117/12.733825 
Author-produced version of the article published in Applied Spectroscopy, 2014, №10 (68), p. 1154-1167. The original publication is available at http://www.ingentaconnect.com

http://dx.doi.org/10.1366/13-07308

Table I: Information measured by standard methods on the algal cultures studied

\begin{tabular}{|c|c|c|c|c|c|}
\hline Sample & $\begin{array}{l}\text { Mean cell } \\
\text { diameter }(\mathrm{ESD}) \\
(\mu \mathrm{m})\end{array}$ & $\begin{array}{l}\text { Cell density in the } \\
\text { medium } \\
\left(\mathrm{m}^{-3}\right)\end{array}$ & $\begin{array}{l}c_{i}(\text { Chl } a) \\
\left.\left(\mathrm{mg} \mathrm{Chla}^{-3}\right)^{-3}\right)\end{array}$ & 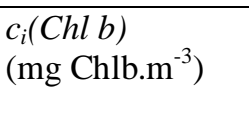 & $\begin{array}{l}c_{i}(\text { Chl tot }) \\
\left(\mathrm{mg} \mathrm{Chla}+\mathrm{b} \cdot \mathrm{m}^{-3}\right)\end{array}$ \\
\hline S1 & $4.3 \pm 0.4$ & $1.5 \pm 0.2 \times 10^{13}$ & $1.73 \pm 0.09 \times 10^{3}$ & $0.62 \pm 0.03 \times 10^{3}$ & $2.32 \pm 0.12 \times 10^{3}$ \\
\hline $\mathrm{S} 2$ & $4.0 \pm 0.4$ & $2.4 \pm 0.2 \times 10^{13}$ & $0.80 \pm 0.04 \times 10^{3}$ & $0.25 \pm 0.01 \times 10^{3}$ & $1.03 \pm 0.05 \times 10^{3}$ \\
\hline S3 & $4.6 \pm 0.4$ & $1.4 \pm 0.1 \times 10^{13}$ & $1.33 \pm 0.07 \times 10^{3}$ & $0.75 \pm 0.04 \times 10^{3}$ & $2.06 \pm 0.11 \times 10^{3}$ \\
\hline S4 & $4.5 \pm 0.4$ & $1.1 \pm 0.1 \times 10^{13}$ & $9.35 \pm 0.47 \times 10^{3}$ & $3.00 \pm 0.15 \times 10^{3}$ & $12.2 \pm 0.6 \times 10^{3}$ \\
\hline
\end{tabular}

Table II: Maxima of absorption identiýed on the absorption spectra and the corresponding $\mu$ values for each sample

\begin{tabular}{|l|c|c|c|c|c|c|}
\hline Peak & $\begin{array}{c}\text { Wavelength } \\
(\mathrm{nm})\end{array}$ & Absorbing species & \multicolumn{4}{|c|}{$\mu\left(\mathrm{mm}^{-1}\right)$} \\
\hline & & & S1 & S2 & S3 & S4 \\
\hline 1 & $436 \pm 2$ & Chl $a$ & $0.097 \pm 0.009$ & $0.084 \pm 0.008$ & $0.092 \pm 0.008$ & $0.11 \pm 0.01$ \\
\hline 2 & $492 \pm 2$ & Chl $b$ & $0.080 \pm 0.008$ & $0.062 \pm 0.007$ & $0.067 \pm 0.008$ & $0.086 \pm 0.008$ \\
\hline 3 & $546 \pm 2$ & & $0.038 \pm 0.007$ & $0.032 \pm 0.008$ & $0.030 \pm 0.006$ & $0.047 \pm 0.007$ \\
\hline 4 & $590 \pm 2$ & $\begin{array}{c}\text { Chl a- Chl c, } \\
\text { Carotenoids }\end{array}$ & $0.039 \pm 0.008$ & $0.034 \pm 0.009$ & $0.032 \pm 0.008$ & $0.044 \pm 0.008$ \\
\hline 5 & $619 \pm 2$ & Chl a & $0.045 \pm 0.008$ & $0.038 \pm 0.008$ & $0.036 \pm 0.008$ & $0.049 \pm 0.008$ \\
\hline 6 & $682 \pm 2$ & Chl a & $0.075 \pm 0.007$ & $0.061 \pm 0.006$ & $0.062 \pm 0.006$ & $0.088 \pm 0.007$ \\
\hline 7 & $842 \pm 2$ & & $0.023 \pm 0.007$ & - & $0.022 \pm 0.007$ & $0.022 \pm 0.007$ \\
\hline 8 & $971 \pm 2$ & Water & $0.064 \pm 0.008$ & - & $0.061 \pm 0.008$ & $0.060 \pm 0.008$ \\
\hline
\end{tabular}

Table III: Comparison of the characteristics of the measured samples to other research works, adapted from Sathyendranath et al. ${ }^{44}$

\begin{tabular}{|c|c|c|c|c|c|c|c|c|c|c|c|}
\hline \multirow{2}{*}{$\begin{array}{l}\text { Sam } \\
\text { ple }\end{array}$} & & \multirow{2}{*}{$\begin{array}{l}\text { Age } \\
\text { (day) }\end{array}$} & \multicolumn{5}{|c|}{ Pigment concentration $\left(\mathrm{mg} \cdot \mathrm{m}^{-3}\right)$} & \multirow{2}{*}{$\begin{array}{l}\text { No. } \\
\text { cells } \\
(\times \\
10 \\
\left.\mathrm{~m}^{-3}\right)\end{array}$} & \multirow{2}{*}{$\begin{array}{l}\text { Mean } \\
\text { diam. } \\
(\mu \mathrm{m})\end{array}$} & \multicolumn{2}{|c|}{$\mathrm{Q}_{\mathrm{a}}$} \\
\hline & & & Chla & Chlb & Pheo & Chlc & Crtnd & & & $\begin{array}{l}440 \\
\mathrm{~nm}\end{array}$ & $\begin{array}{l}737 \\
\mathrm{~nm}\end{array}$ \\
\hline S1 & $\begin{array}{l}\text { Scenedesmus + } \\
\text { Chlorella }\end{array}$ & - & $1730 \pm 90$ & $620 \pm 30$ & - & - & - & $\begin{array}{l}1.5 \\
\pm 0.2 \\
\times 10\end{array}$ & $4.3 \pm 0.4$ & $\begin{array}{c}0.4 \pm \\
0.1\end{array}$ & $\begin{array}{c}0.11 \\
\pm \\
0.04\end{array}$ \\
\hline S2 & $\begin{array}{l}\text { Scenedesmus + } \\
\text { Chlorella }\end{array}$ & - & $800 \pm 40$ & $250 \pm 10$ & - & - & - & $\begin{array}{l}2.4 \\
\pm 0.2 \\
\times 10\end{array}$ & $4.0 \pm 0.4$ & $\begin{array}{c}0.27 \\
\pm \\
0.07\end{array}$ & - \\
\hline S3 & $\begin{array}{l}\text { Scenedesmus + } \\
\text { Chlorella }\end{array}$ & - & $1330 \pm 70$ & $750 \pm 40$ & - & - & - & $\begin{array}{l}1.4 \\
\pm 0.1 \\
\times 10\end{array}$ & $4.6 \pm 0.4$ & $\begin{array}{c}0.4 \pm \\
0.1\end{array}$ & $\begin{array}{c}0.09 \\
\pm \\
0.04\end{array}$ \\
\hline S4 & $\begin{array}{l}\text { Scenedesmus + } \\
\text { Chlorella }\end{array}$ & - & $9350 \pm 470$ & $3000 \pm 150$ & - & - & - & $\begin{array}{l}1.01 \\
\pm 0.1 \\
\times 10\end{array}$ & $4.5 \pm 0.4$ & $\begin{array}{c}0.7 \pm \\
0.1\end{array}$ & $\begin{array}{c}0.15 \\
\pm \\
0.05\end{array}$ \\
\hline 5 & $\begin{array}{l}\text { Platymonas } \\
\text { suecica }\end{array}$ & 3 & 138 & 42.3 & 5.1 & 0 & 114 & 26 & 5.8 & 0.671 & 0.080 \\
\hline 6 & $\begin{array}{l}\text { Platymonas } \\
\text { suecica }\end{array}$ & 7 & 245 & 131 & 46.5 & 0 & 261 & 49 & 5.6 & 0.837 & 0.103 \\
\hline 7 & $\begin{array}{l}\text { Dunaliella } \\
\text { marina }\end{array}$ & 7 & 225 & 88.8 & 27.2 & 0 & 219 & 16 & 8.5 & 0.979 & 0.197 \\
\hline 8 & $\begin{array}{l}\text { Tetraselmis } \\
\text { maculata }\end{array}$ & - & 467 & 231 & 0 & 0 & 435 & 90 & 8.5 & 0.465 & 0.079 \\
\hline 9 & Platymonas sp. & - & 624 & 298 & 25.3 & 0 & 662 & 207 & 6.8 & 0.472 & 0.102 \\
\hline 10 & $\begin{array}{l}\text { Hymenomonas } \\
\text { elongata }\end{array}$ & 7 & 247 & 0 & 23.6 & 49.1 & 233 & 5.8 & 13.4 & 0.765 & 0.080 \\
\hline
\end{tabular}


Author-produced version of the article published in Applied Spectroscopy, 2014, №10 (68), p. 1154-1167.

The original publication is available at http://www.ingentaconnect.com

http://dx.doi.org/10.1366/13-07308

\begin{tabular}{|c|l|c|c|c|c|c|c|c|c|c|c|}
\hline 11 & $\begin{array}{l}\text { Hymenomonas } \\
\text { elongata }\end{array}$ & 9 & 384 & 0 & 7.5 & 79 & 333 & 8.1 & 13.5 & 0.693 & 0.021 \\
\hline 12 & $\begin{array}{l}\text { Hymenomonas } \\
\text { elongata }\end{array}$ & 14 & 781 & 0 & 10.3 & 166 & 640 & 17 & 14 & 0.618 & 0.034 \\
\hline 13 & $\begin{array}{l}\text { Hymenomonas } \\
\text { elongata }\end{array}$ & 17 & 1019 & 0 & 22.7 & 300 & 769 & 23 & 15.1 & 0.507 & 0.034 \\
\hline 14 & $\begin{array}{l}\text { Chaetoceros } \\
\text { protuberans }\end{array}$ & 1 & 172 & 0 & 14.9 & 95.6 & 73.4 & 7.5 & 9.5 & 0.941 & 0.090 \\
\hline
\end{tabular}

